\title{
A simple methodology for comparing cost-benefit of traditional, green and cool roofs
}

\author{
Diletta Di Lorenzo ${ }^{1}$, Valeria Lupo', Giorgia Peri $^{1, *}$, Gianfranco Rizzo ${ }^{1}$, and Gianluca Scaccianoce ${ }^{1,2}$ \\ ${ }^{1}$ University of Palermo, Department of Engineering, viale delle Scienze, 90128 Palermo, Italy. \\ 2 National Research Council of Italy, Institute of Biomedicine and Molecular Immunology, via Ugo La Malfa 153, 90146 Palermo, Italy.
}

\begin{abstract}
Energy policy makers, architects and researchers, when designing new buildings or rehabilitating the existing ones, are engaged in the attempt of limiting the energy needs for climatization (NZEB buildings) and the environmental pressure exerted by buildings (EU Climate Action). The pursuit of this demanding assignment calls for innovative solutions in conceiving the building envelope and its energy systems. Recently, among the most effective tools for improving the energy and environmental performances of buildings, the technical interventions regarding the roofs are gaining a rising attention. Indeed, covers of buildings are responsible of a relevant part of their energy losses and, on the other hand, could contribute to increasing the UHI effect. In the paper, a simple methodology that compares the energy and environmental benefits of cool and green coverages with traditional ones is presented. The capability of limiting the UHI effect of these solutions is also analysed. The methodology is applied to four cities of the Sicilian Island, characterized by different building density and different microclimates. This in-field application shows the feasibility of the method to be used in different urban contexts, as a useful contribution to the design of new buildings or to the re-design of the existing ones.
\end{abstract}

\section{Introduction}

Energy policy makers, architects and researchers are facing two main challenges in their important task of designing new buildings or rehabilitating the existing ones: limiting both the energy needs for climatization (NZEB buildings) and the environmental pressure exerted by buildings (EU Climate Action). Moreover, these purposes should be achieved without compromising the indoor comfort conditions, which must be guaranteed to occupants, anyway. The pursuit of such demanding assignments calls for innovative solutions in conceiving the building envelope and its energy systems.

Additionally, by a wider point of view, each building should be regarded as a node of an urban network that both demands a given amount of energy and exerts a certain pressure on the environment.

Recently, among the most effective available tools for improving the energy and environmental performances of buildings, the technical interventions regarding the roofs are gaining a rising attention. Indeed, covers of buildings are responsible for a relevant part of their energy losses and, on the other hand, when not properly designed, could contribute to increasing the Urban Heat Island (UHI) effect.

The well-known phenomenon of the UHI is a typical and significant example of the way with which buildings can modify (actually worsen) the local climate of cities.
The UHI intensity, defined as the difference in temperature between an urban site and its surrounding rural site [1], exerts a twofold effect on buildings [2]. On one hand, in fact, cooler roof surfaces determine a reduced amount of the short-wave solar radiation absorbed and transmitted toward the indoor spaces through the building structure. On the other hand, a green surface (particularly when interesting wide extension of coverages) contributes to the reduction of the urban air temperature.

Therefore, one of the possibilities for limiting the contribution of a given building to the UHI generation is to boost its roof albedo. In this way, in fact, the amount of solar radiation absorbed by the roof is reduced and this in turn would prevent an overheating of the roof. This goal could therefore be achieved by installing a green roof on the top of the building: not by chance, the skyline of the cities is rapidly changing, showing a large diffusion of green coverage surfaces. Anyway, a cool roof could obtain similar results, but with less expensive interventions on the building envelope. Which of these two interventions is better then?

In this paper, a simple methodology that compares the energy and environmental benefits of cool and green coverages with a traditional one is presented. The capability of limiting the UHI effect of these solutions is compared as well. The methodology is applied to four cities of the Sicilian Island, which are characterized by different building density and different microclimates.

\footnotetext{
* Corresponding author: peri@dream.unipa.it
} 
The in-field application shows the feasibility of the method for utilizations in different urban contexts, in this way effectively contributing to the design of new buildings or to the re-design of the existing ones.

\section{Urban Heat Island and buildings albedo}

The relationships between UHI phenomena and the albedo of the roofs of buildings have been since long time investigated, particularly referring to the cooling season. Akbari et al. [3] have analysed the cooling-energy savings potential induced by reflective roof surfaces in the United States and have calculated the energy-saving potentials [4] of different strategies aimed at the heat-island reduction. Due to their recognized effectiveness in improving the performance of commercial buildings, potential benefits of cool roofs have been extensively investigated over the whole United States territory [5] in terms of conservation of energy, saving of money and reduction of greenhouse gas emission. Referring to their economic effectiveness, the possible mitigation of UHI phenomena has been analysed [6] by means of a calculation tool able to estimate the electrical energy savings induced by the installation of (roof) cooler surfaces in a typical warm city in California [7].

It is important to note that heat island phenomena are generated in urban contexts regardless the dimension of the cities [8]: therefore, when designing buildings, methods of analysis are increasingly necessary in view of accounting for new and more effective technologies aimed at lowering the environmental impact of this relevant sector of the human lives.

Generally, the tools for investigating the effect of green roof surfaces on the UHI mitigation rely on meteorological simulation approaches, aimed at suitably assessing the energy budget of the canopy. A typical and largely used tool of this type is represented by the Weather Research and Forecasting (WRF) model [9], which properly takes into account the reflections among different urban surfaces and between these and the atmosphere. Recently, this approach has been applied to the area of Rome [10], whose urban climate is modelled in order of evaluating the modification of the UHI intensity subsequent to an increase of the albedo of the horizontal surfaces of the built area.

Other effective methods pay their attention on the difference between temperatures of land surface and impervious surface areas [11], by means of remote sensing observations.

\section{Proposal of a simple method of evaluation}

Apart the urban-scale effects on the UHI phenomena, the adoption of green roofs among the construction components should also provide benefits at the buildingscale, particularly referring to the possible energy savings that they induce [12]. With this aim in mind, technicians must have at their own disposal useful calculation methods able to easily establishing the relationship between the building technology choices and the effects, not only on the UHI intensity, but also on the energy demand (and, possibly, the indoor comfort performances) of the analysed buildings. One of the most important parameters on which the energy demand of a building depends is represented by the outdoor surface temperature of the envelope components. This, in fact, is the driving indicator for effectively assessing the thermal balance of a given premise and in turn for estimating the heat flux entering the building (by means of the computation of the internal temperatures of the envelope stratigraphy, until the indoor surface one). As far the coverage of a building is in context, the most relevant parameter is constituted by the surface temperature of the roof. This clearly depends on both the climatic conditions of the given site and the type of the roof coverage. Obviously, traditional, cool or green roofs will establish different outdoor surface temperatures, leading thus to different consequences on the UHI effects of a given urban context.

Starting from these considerations, here we propose a simple method aimed at both providing the outdoor surface temperature of roofs with different characteristics and colours and singling out the indoor surface temperatures of the same building components, by taking into account the dynamic feature of the microclimatic urban conditions. This parameter, apart their direct links with the energy and indoor performances of a building, is evidently an important driver for the setting-up of UHI phenomena. Indeed, significant increases in the air temperature near roofs have been detected, depending on the type of materials and the hours of the day (Figure 1), in this way signalling the role of different materials on the UHI formation [13].

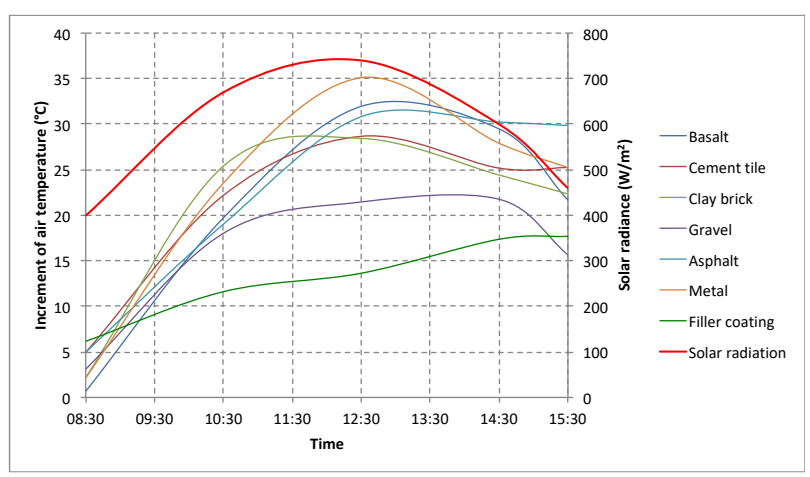

Fig. 1. Typical hourly increases of the air temperature above different roof materials.

The proposed method aims at assessing a simple calculation path for defining the energy savings produced in the climatization of buildings by the substitution of traditional roofs with cooler coverages, either cool or green roofs. Specifically, the method pays a particular attention to the assessment of the entity of the decrease of the indoor and outdoor roof surface temperatures, due to the adoption of higher values of the albedo of the building coverage.

Figure 2 illustrates the main steps of the procedure that, starting from a given traditional roof, leads to the adoption of more reflective roof surfaces and, therefore, 
to both the contemporary decrease of the UHI intensity and the saving of electric energy for cooling buildings.

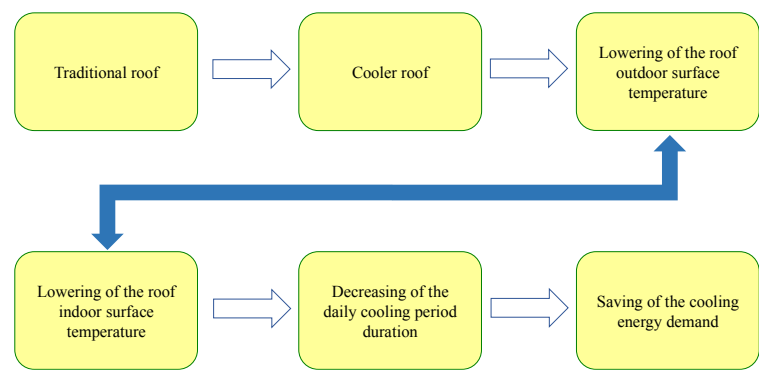

Fig. 2. From cooler surfaces to cooling energy savings: stepby-step procedure.

The main physical parameters, which the procedure relies on, are the outdoor surface temperature of the roof $\left(\mathrm{T}_{\mathrm{or}}\right)$ and the indoor surface temperature of the ceiling $\left(\mathrm{T}_{\mathrm{ic}}\right)$. The first one is, in fact, a crucial indicator to be controlled in order of limiting the UHI phenomena. The second one, on the other side, provides an important contribution to achieve the indoor thermal comfort/discomfort conditions. Both methods for computing these surface temperatures are presented in the following.

\subsection{Computing the roof outdoor surface temperature}

It is well known that the outdoor temperature of a building component (the roof, in this case) is determined by the balance of the involved energy contributions, namely the incoming $\left(\mathrm{q}_{\mathrm{irr}}\right)$ and reflected $\left(\mathrm{q}_{\mathrm{ref}}\right)$ solar radiation, the convective fluxes $\left(\mathrm{q}_{\text {conv }}\right)$ activated by the outdoor air velocity and direction, the infrared re-irradiated ( $\left.q_{\text {reir }}\right)$ heat and the heat transmitted through the roof stratigraphy inside the building by conduction ( $\left.\mathrm{q}_{\text {cond }}\right)$. That is:

$$
q_{\text {irr }}-q_{\text {ref }}-q_{\text {conv }}-q_{\text {reir }}-q_{\text {cond }}=0
$$

All terms of Equation 1 depend on the outdoor air temperature, $T_{o a}$, which determines the conditions for the UHI formation, while the convective rate of the balance,

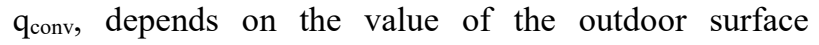
temperature of the roof, $T_{o r}$. This latter represents the physical quantity being object of the present study and is strongly determined by the value of the albedo of the outdoor surface of the roof. In fact, the effects produced by different coverages on the UHI are here compared based on their different albedo values.

By means of the energy balance provided by Equation 1 it is possible to compute the "skin" temperature of the building roofs of the considered urban contexts. The maximum value of the monthly mean solar irradiance and the maximum value of the monthly mean air temperature in the summer season are used to compute the terms of the energy balance for each type of roof taken into account in the present analysis. Finally, the characteristic air temperature of a given city is given by the average of those of the different roof typologies, weighted with their percentage extension on the urban contest under analysis.

\subsection{Defining the roof indoor surface temperature}

The value of the indoor surface temperature of the roof (that is the indoor one of the ceiling of the building) depends on the outdoor surface temperature and on the thermo-physical properties of the ceiling compound. The given roof stratigraphy produces a double effect on the thermal flux coming from the outdoors: an attenuation of the value and a delay in the arrival of the thermal wave at the indoor surface of the ceiling. Obviously, this phenomenon is complex and involves the dynamic behavior of the energy contributions affecting the building balance, particularly in the summer season when the fast change of the solar radiation hitting the building envelope determines an important time-depending feature of the heat flows.

The delay $D$ (s) of the thermal flow, with which it achieves the indoor surface of the ceiling after hitting the outdoor surface of the roof, is given by the summation of the delays of each single layer constituting the roof compound. Being $v(\mathrm{~m} / \mathrm{s})$ the velocity of the heat thermal flow of the $i$-th layer characterized by a thickness $s_{\mathrm{i}}(\mathrm{m})$, the delay can then be computed as follows:

$$
D=\Sigma D_{i}=\Sigma\left(s_{i} / v_{i}\right)
$$

The velocity $v_{i}$ is in turn given by:

$$
v_{i}=\left[\lambda_{i} /\left(\rho_{i} c_{p i}\right)(2 \omega)\right]^{1 / 2}
$$

where for each $i$-th layer $\lambda_{i}$ is the thermal conductibility $(\mathrm{W} / \mathrm{m} \mathrm{K}), \rho_{i}$ is the density $\left(\mathrm{kg} / \mathrm{m}^{3}\right)$ and $c_{p i}$ is the specific heat $(\mathrm{J} / \mathrm{kg} \mathrm{K})$. The term $\omega$ represents the pulsation of the heat wave.

The attenuation of the amplitude of the heat wave, $\sigma$, is defined as the ratio between the semi-amplitudes of the heat wave entering (from outside) and that of the heat wave leaving (toward indoors) the roof.

Starting from these two parameters, the temperature value of the indoor surface of the ceiling, $T_{i c}$, is simply given by:

$$
T_{i c}=\left(T_{o r, \max }+T_{o r, \min }\right) / 2+\sigma\left(T_{o r, \max }-T_{o r, \min }\right) / 2
$$

being $T_{\text {or, } \max }$ and $T_{\text {or, } \min }$ the maximum and minimum temperature of the outdoor surface of the roof, respectively.

\subsection{Geo-referencing of the territory from satellite images}

Since the UHI phenomena involve (large) urban areas with their building coverages features, a geo-referencing of the analyzed land is needed. The present procedure is developed also through the recourse to satellite images.

On purpose, an $\operatorname{ArcGis}^{\odot}$ environment is used here, by means of the reference system Roma $40^{\circ}$, associated to the cartographic system Gauss-Boaga [14] (the official 
method used in Italy and based on the Universal Trasversal Mercator projection). The datum is given by the ellipsoid of Hayford, referring to the Monte Mario releasing center. By assigning the Gauss-Boaga system to the satellite images, it is possible to manage the so-called Ground Control Points, thus achieving the complete georeference of the considered territory. This in turn allows the generation of a geographic database of the examined area that is structured by applying an Arc Catalog ${ }^{\odot}$.

By means of the above-described geo-referencing procedure the urban Sicilian region is sub-divided into three main typologies: built surfaces, street surfaces and urban green. In this way, a map reporting the percentage distribution of these typologies of territory can be drawn for the 110 towns showing a population greater than 10,000 inhabitants (Figure 3).

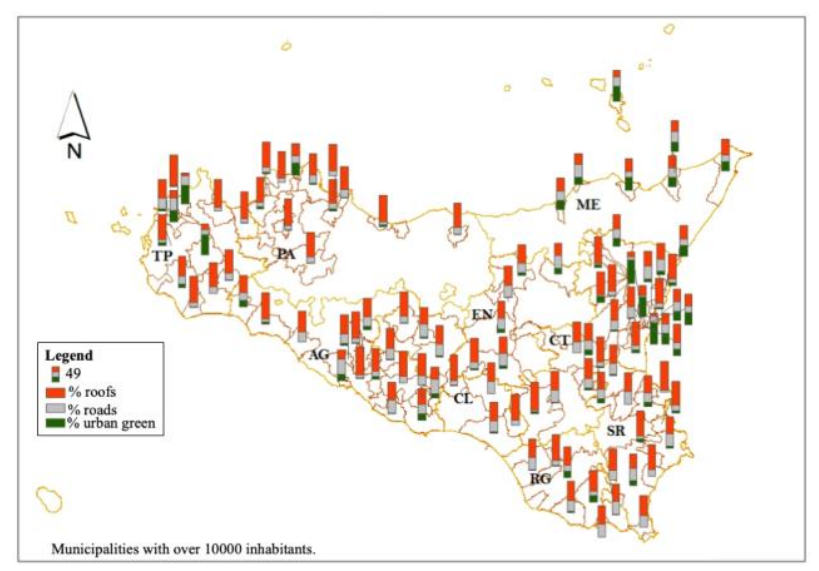

Fig. 3. Percentage distribution of the typologies of urban surfaces for cities having more than 10,000 inh.

This framework also enabled us (thanks to satellite images) to single out the percentage distribution of the three mainly utilized typologies of roof in urban areas: pitched roofs of brick tiles, pitched roofs of asphalt shingle and flat concrete roofs. Figure 4 depicts this distribution for the above-considered cities in Sicily. It is evident the different dissemination of these roof technologies along the Island.

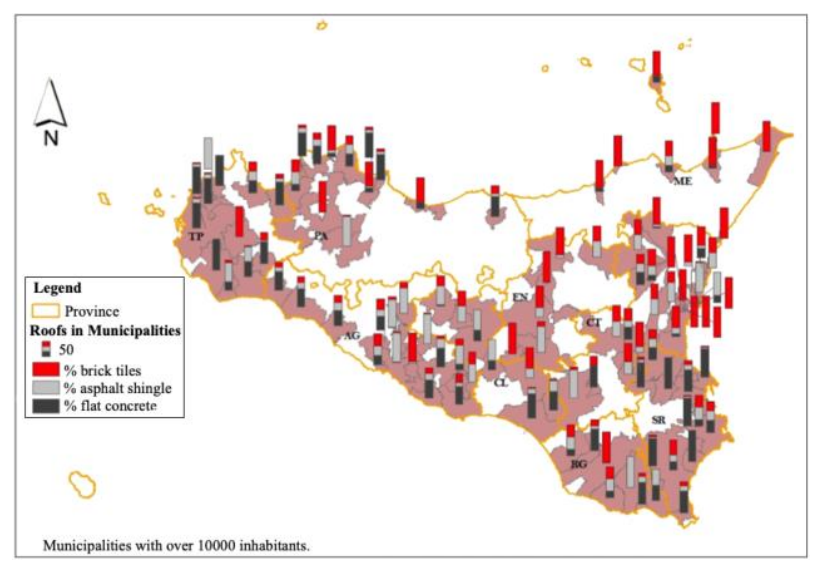

Fig. 4. Percentage distribution of the mainly used typologies of roof in the most populated Sicilian cities.

\section{Application to four urban contexts}

Clearly, the heat island phenomena occur in almost any urban context but they are more evident and relevant in the highly concentrated urban settlements. Therefore, the proposed methodology has been applied to four of the biggest cities in Sicily that is Palermo, Catania, Messina and Trapani, where it is expected that the role of the built environment could remarkably affect the formation of significant heat island episodes. Apart their nearly similar urban layouts, all these cities are characterized by some common conditions that we have tentatively assumed as potential causes of intense UHI phenomena. That is: a temperature difference between urban and rural sites greater than $6{ }^{\circ} \mathrm{C}$; a mean wind speed less than $6 \mathrm{~m} / \mathrm{s}$; a shape factor (that is the ratio between built an non-built volumes of the city) greater than 0.5 .

The energy balance given by Equation 1 clearly depends on some relevant thermal and radiative parameters of the external layer of the roofs, like emissivity, absorbance and albedo of materials. Table 1 reports the values adopted for the simulations.

Table 1. Thermal and radiative parameters of the considered roof compounds (data of the last three rows were used to simulate the different scenarios).

\begin{tabular}{|c|c|c|c|}
\hline 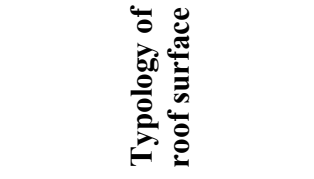 & 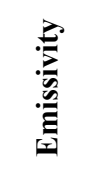 & 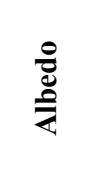 & 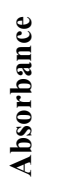 \\
\hline $\begin{array}{l}\text { Pitched roofs of brick } \\
\text { tiles }\end{array}$ & 0.850 & 0.350 & 0.650 \\
\hline $\begin{array}{l}\text { Pitched roofs of asphalt } \\
\text { shingle }\end{array}$ & 0.860 & 0.210 & 0.790 \\
\hline Flat concrete roofs & 0.890 & 0.100 & 0.900 \\
\hline $\begin{array}{l}\text { Pitched cool roofs (with } \\
\text { polymeric painting) }\end{array}$ & 0.880 & 0.795 & 0.205 \\
\hline $\begin{array}{l}\text { Flat cool roofs (with } \\
\text { synthetic membrane) }\end{array}$ & 0.900 & 0.827 & 0.173 \\
\hline Green roofs & 0.980 & 0.500 & 0.500 \\
\hline
\end{tabular}

The analysis of these four selected urban contexts has been conducted with reference to a standard residential module, as indicated by the Italian regulation [15], while the characteristics of the vegetated layer of the green roof refer to the typical design habits in Sicily $[16,17]$ for this kind of technology.

Preliminarily, we have computed the external surface temperature of the usual and recurrent roof covers in the cities, as reported in Figure 5. The values for brick tiles, shingle, cement and asphalt covers are compared with the value of the mean temperature of green surfaces outside the urbanized areas of the cities: these green surfaces represent the reference areas for establishing (by assessing the air temperature difference between built and non-built zones) the entity of the UHI in the urban contexts.

As it is possible to observe, generally these typologies of coverings determine high values of the temperature of the roofs surface. 


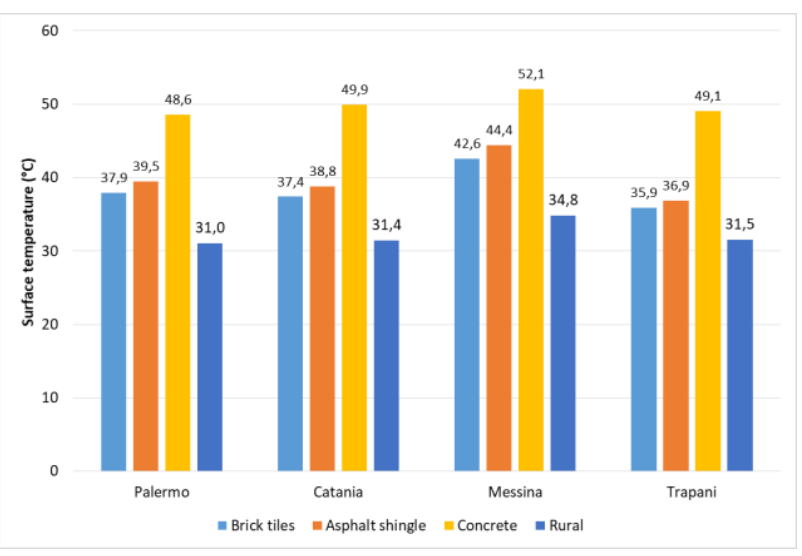

Fig. 5. Surface temperature of the typical roofs and of reference rural surfaces.

These temperature data, along with the percentage distribution of the coverages in each city, allow the evaluation of the mean temperature $\left(\mathrm{T}_{\mathrm{UHI}}\right)$ of the urban roof surfaces that in turn are responsible of the UHI phenomena. The computed mean surface temperature $\mathrm{T}_{\mathrm{UHI}}$ for the considered urban areas are those reported in Table 2.

Table 2. Mean temperature ( $\mathrm{T}_{\mathrm{UHI}}$ ) of the urban roof surfaces.

\begin{tabular}{|l|c|}
\hline \multicolumn{1}{|c|}{ Urban area } & $\begin{array}{l}\mathrm{T}_{\mathrm{UHI}} \\
\left({ }^{\circ} \mathrm{C}\right)\end{array}$ \\
\hline Catania & 38.9 \\
\hline Messina & 42.0 \\
\hline Palermo & 41.3 \\
\hline Trapani & 41.3 \\
\hline
\end{tabular}

Clearly, the mean temperatures of the urban roofs in the present situation are certainly very high, with the consequence of possible undesired values of the UHI of the areas. Therefore, proper countermeasures should be assumed, in order of lowering the outside surface temperatures of the roofs.

On purpose, here we have hypothesized three different scenarios involving the roofs and referring to materials reported in the last three rows of Table 1. In the Scenario 1 , all the roof surfaces are covered with cool materials; in the Scenario 2 all the flat roofs are equipped with green surfaces, while the remaining (sloping) surfaces are those of the status quo ("traditional" roof); in the Scenario 3 all the flat roofs are equipped with green surfaces, while the remaining (sloping) surfaces are covered with cool materials.

Figure 6 depicts, for the four considered cities, the new values of the mean $\mathrm{T}_{\mathrm{UHI}}$ of the roof surfaces achieved in the three coverage scenarios and compares these latter with the starting values of the status quo situation.

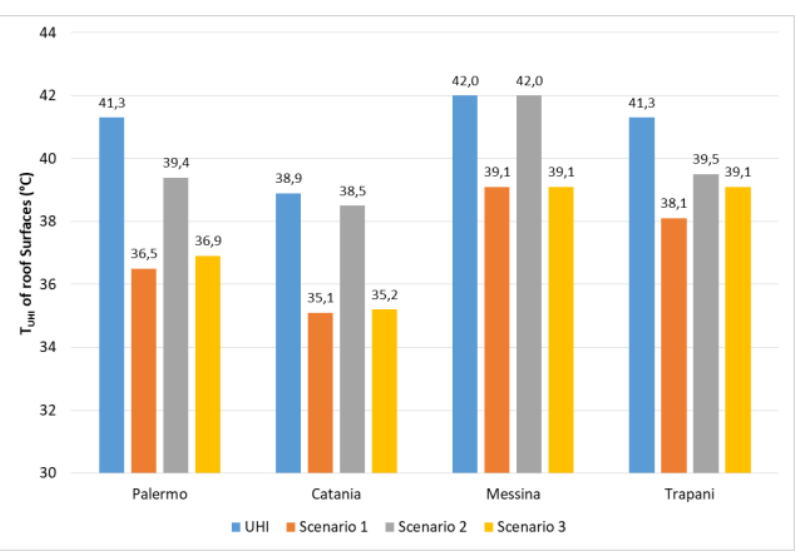

Fig. 6. Surface temperature of the modified roofs, compared with the TUHI.

As it is possible to note, the proposed technological changes from the original situations (pitched roofs of brick tiles, pitched roofs of asphalt shingle and flat concrete roofs) interestingly decrease the temperature of the roof surfaces. Specifically, the Scenario 1 (cool materials) and the Scenario 3 (mix of green and cool roofs) show the best performances compared to the Scenario 2 (mix of green and "traditional" roofs). Anyway, all the proposed scenarios determine a remarkable lowering of the original roof temperature, with a very likely mitigation of the UHI phenomena.

\section{Conclusions}

The mean values of the $T_{\mathrm{UHI}}$ temperatures, computed by means of the simple procedure presented here, represent parameters that can be usefully adopted by urban planners and technicians for a twofold purpose. On one hand, in fact, these parameters represent a clear indication of the possible establishment of UHI phenomena. On the other hand, these values are a direct checking of the possible UHI mitigation deriving from technological change of the buildings' coverages of the urbanized areas.

Obviously, Equation 1 is only a simplified description of the energy and thermal phenomena occurring between the roof and the urban environment. In fact, in this algorithm the latent heat exchanges by evapotranspiration are not taken into account, being the emphasis given only to the dry heat exchanges. Anyway, the Equation 1 can be considered as a useful starting point for modeling the roof-environment system in order of getting a draft evaluation of the surface temperature of the roof. Clearly, further physical phenomena can be modeled by introducing a high level of complexity in the tool that, in a preliminary stage of the design procedure, is not strictly necessary.

This work was carried out within the research project $n$. 201594LT3F, "La ricerca per i PAES: una piattaforma per le municipalità partecipanti al Patto dei Sindaci (Research for SEAP: a platform for municipalities taking part in the Covenant of Mayors)", which is funded by the PRIN (Programmi di Ricerca Scientifica di Rilevante Interesse Nazionale) of the Italian Ministry of Education, University and Research. 


\section{References}

1. G. Levermore, J. Parkinson, K. Leeb, P. Laycock, S. Lindley, Urban Climate 24 (2018).

2. A. Baniassadi, D. J. Sailor, P. J Crank, G. A BanWeiss, Energ Buildings 178 (2018).

3. H Akbari, S. Konopacki, M. Pomerantz, Energy, 24 (1999).

4. H. Akbari, S. Konopacki, Energ Policy 33 (2005).

5. R. Levinson, H. Akbari, Energ Effic 3, 1 (2010).

6. M. Pomerantz, Urban Climate 24 (2018).

7. M. Pomerantz, P.J. Rosado, R. Levinson, Urban Climate 14 (2015).

8. I.D. Stewart, T.R. Oke, Bull. Am. Meteorol. Soc. $\mathbf{9 3}$ (2012).

9. WRF User Guide, Chapter 3: WRF Preprocessing System (WPS). Land use and soil categories in the static data http://www2.mmm.ucar.edu/wrf/users/docs/user_g uide_V3/users_guide chap3.htm (2009).

10. E. Morini, A. G. Touchaei, F. Rossi, F. Cotana, H. Akbari, Urban Climate 24 (2018).

11. H. Li, Y. Zhou, X. Li, L. Meng, X. Wang, S. Wu, S. Sodoudi, Sci Total Environ 624 (2018).

12. V. Costanzo, G. Evola, L. Marletta, Energ Buildings 114 (2016).

13. M. Pomerantz, H. Akbari, A. Chen, H. Taha and A. H. Rosenfeld (Lawrence Berkeley National Laboratory, LBNL-38074, Berkeley, CA, 1997).

14. Monti C., 1984, Elementi di cartografia con riferimenti alla situazione cartografica in Italia, in "Spazi verdi territoriali. Corso post-laurea di formazione professionale - Milano, 1983", pp. 92142, (Franco Angeli editore, Milano, 1984).

15. Decreto del 26 giugno 2015 del Ministro dello sviluppo economico di concerto con i Ministri dell'ambiente e della tutela del territorio e del mare, delle infrastrutture e dei trasporti, della salute e della difesa: "Applicazione delle metodologie di calcolo delle prestazioni energetiche e definizione delle prescrizioni e dei requisiti minimi degli edifici". (in Italian)

16. M. La Gennusa, G. Peri, G. Rizzo, G. Scaccianoce, P. Jones, Energ Buildings 129 (2016).

17. P. Ferrante, M. La Gennusa, G. Peri, G. Rizzo, G. Scaccianoce, Energy 115 (2016).

\begin{tabular}{|c|c|c|}
\hline \multicolumn{3}{|l|}{ Nomenclature } \\
\hline $\begin{array}{l}\text { Outdoor surface temperature of } \\
\text { the roof }\end{array}$ & $\mathrm{T}_{\text {or }}$ & ${ }^{\circ} \mathrm{C}$ \\
\hline $\begin{array}{l}\text { Indoor surface temperature of } \\
\text { the ceiling }\end{array}$ & $\mathrm{T}_{\mathrm{ic}}$ & ${ }^{\circ} \mathrm{C}$ \\
\hline Incoming solar radiation & $\mathrm{q}_{\text {irr }}$ & $\mathrm{W} / \mathrm{m}^{2}$ \\
\hline Reflected solar radiation & $\mathrm{q}_{\mathrm{ref}}$ & $\mathrm{W} / \mathrm{m}^{2}$ \\
\hline Convective flux & qconv & $\mathrm{W} / \mathrm{m}^{2}$ \\
\hline Infrared re-irradiated heat & $\mathrm{q}_{\text {reir }}$ & $\mathrm{W} / \mathrm{m}^{2}$ \\
\hline Heat conduction flux & $\mathrm{q}_{\mathrm{cond}}$ & $\mathrm{W} / \mathrm{m}^{2}$ \\
\hline Outdoor air temperature & $\mathrm{T}_{\mathrm{oa}}$ & ${ }^{\circ} \mathrm{C}$ \\
\hline Delay of the thermal flow & $D$ & $\mathrm{~s}$ \\
\hline $\begin{array}{l}\text { Velocity of the heat thermal } \\
\text { flow }\end{array}$ & $v$ & $\mathrm{~m} / \mathrm{s}$ \\
\hline Layer thickness & $s$ & $\mathrm{~m}$ \\
\hline Thermal conductibility & $\lambda$ & $\mathrm{W} /(\mathrm{mK})$ \\
\hline Density & $\rho$ & $\mathrm{kg} / \mathrm{m}^{3}$ \\
\hline Specific heat & $c_{p}$ & $\mathrm{~J} /(\mathrm{kgK})$ \\
\hline Pulsation of the heat wave & $\omega$ & $\mathrm{rad} / \mathrm{s}$ \\
\hline $\begin{array}{l}\text { Attenuation of the heat wave } \\
\text { amplitude }\end{array}$ & $\sigma$ & - \\
\hline $\begin{array}{l}\text { Maximum outdoor surface } \\
\text { temperature of the roof }\end{array}$ & $T_{s, \max }$ & ${ }^{\circ} \mathrm{C}$ \\
\hline $\begin{array}{l}\text { Minimum outdoor surface } \\
\text { temperature of the roof }\end{array}$ & $T_{s, \min }$ & ${ }^{\circ} \mathrm{C}$ \\
\hline $\begin{array}{l}\text { Mean temperature of the urban } \\
\text { roof surfaces }\end{array}$ & $\mathrm{T}_{\mathrm{UHI}}$ & ${ }^{\circ} \mathrm{C}$ \\
\hline
\end{tabular}

